\title{
PUBLIC INFORMATION STANDARTS, INTELLECTUAL PROPERTY RIGHTS AND ECONOMIC DEVELOPMENT
}

\author{
SHQIPE DUMI ${ }^{1}$ PROF.DR.ALBA DUMI ${ }^{2}$ \\ ${ }^{1}$ Universite Jean Moulin, Lyon 2, France \\ ${ }^{2}$ Vice Dean of TBU, University of Tirana, Albania
}

Email:alba.besi12@gmail.com

\begin{abstract}
This paper looks at Intellectual Property Rights and the relation they have with economic growth. It also reveals the instruments of Intellectual Property Rights and their impact on the developing and developed countries. At the end it analyzes where Kosovo stands in regards to Intellectual Property rights and what are the steps that should be taken for the situation to improve. Intellectual property is an old concept.

Intellectual Property Rights is one strong point for developing the economic growth all over the world. On the other hand in this study we are trying to investigate the progress of the Intellectual Property Rights in Albania and in Kosovo institutions and government progressing reforms. The findings of this paper are some data, gathering in statistical analyze.

Intellectual Property Rights in now days is not an old concept, but it evaluate with improving low reforming. The conclusions of this paper research consist in: The infrastructure and technological advancement in this country is still weak, therefore major innovations and discoveries are unlikely to happen (Kosovo case) In Albania the situation is in perfection wnder low influences.
\end{abstract}

Key words: Economy performance, economy development,economic growth, intellectual property rights, patents,innovation

\section{Introduction}

Economic growth is a goal that almost all countries seek vigorously. The increase in output that results in higher real incomes of workers, improve citizens' standard of living. This way, the gap between peoples' wants and scarcity is less severe. For a country like Kosovo, economic growth should be a priority and perhaps the most important goal of the government (Larry 1999')there have been numerous cases where countries with much weaker economy managed to gradually improve and eventually surpass the most developed countries. According to the US Bureau of East Asian and Pacific Affairs ${ }^{2}$, Singapore managed to achieve an average growth rate of 7.8 percent between 1965 and 2009, despite the lack of physical resources ("Background Note: Singapore", par. $\left.15^{3}\right)^{4}$. This enabled Singapore to become one of the richest countries worldwide, with an estimated per-capita GDP of \$35,515 ("Background Note: Singapore", par. 1).

Japan, Hong Kong, and South Korea have also experienced immense economic growth similar to that of Singapore. This proves that even smaller and poorer countries can catch up with industrialized, wealthy countries. ${ }^{5}$ However, between 1750 and 1870, Europe underwent profound changes, which among others can include: growth of cities, construction of railways, capital investment and increased transatlantic economy. However, in Europe the main elements of intellectual property were still in their infancy.

\footnotetext{
${ }^{1}$ Larry 1999

${ }^{2}$ US Bureau of East Asian and Pacific Affairs

${ }^{3}$ Background Note: Singapore", par. 15, pp 23

${ }^{4}$ Please refer to http://www.state.gov/r/pa/ei/bgn/2798.htm for the full article on Singapore.

${ }^{5}$ Lewinn 2009
} 
While the American colonies had laws that give patents long before the outbreak of the American Revolution in $1775^{6}$, and soon after the revolution, 12 of the 13 original colonies adopted laws on copyright.Kosovo should follow the path that these countries followed and analyze what they have done that worked so well for them. In general, many factors or institutional structures might foster economic growth, one of them believed to be the protection of intellectual property rights. But is this necessarily the case?

\section{INFORMACION I PERGJITHSHEM}

Në dekadën e kaluar,një numër i paparashikueshëmvendesh nëpër botë krijuan legjislacionin për lirinë e informimit përfshirë Britaninë e Madhe, Afrikën e jugut, Meksikën etj dhe shumë vënde të tjera nga Europa Lindore dhe Qëndrore. Në këtë mënyrë këto vende iu bashkuan vendeve që e kishin krijuar këtë legjislacion prej kohësh të tilla si SHBA, Australia, Kanada, Hollanda. Vetë ligji gjithsesi është vetëm hapi i parë. ${ }^{7}$ Zbatimi i ligjit duke mbajtur parasysh detyrën e transformimt të kulturës së administratës në një kulturë më demokratike dhe të qëndrueshme përmban një ndryshim të madh, veçanërisht në vendet me ekonomi të rrënuar ku buxhetet e shtetit për zbatimin e një programi bashkohor janë të kufizuara. Në shumë demokraci në zhvillim si në Shqipëri, njohja formale e të drejtës së informimit nuk është transmetuar gjithmonë dhe domosdoshmërisht në jetën e përditshme për qytetarët, kjo për shkak të mungesës së zbatueshmërisë.

Që nga 1999 Shqipria $^{8}$ e ka patur ligjin e lirisë së informacionit.Në lidhje me një demokraci politike efektive dhe respektimin për të drejtat e njeriut,e drejta për t'u informuar nuk mbart rëndësi vetëm në vetvete por gjithashtu luan nje rol qëndror në mbrojtjen e të drejtave të tjera. Nuk ka vend të lirë , nuk ka demokraci pa pasur një garantim të gjërë të së drejtës për t’u informuar.Ajo përbën një nga themelet thelbësore të një shoqërie demokratike, një nga kushtet bazë për progresin e saj dhe për zhvillimin e çdo qënieje njerëzore.

Objektivat e këtij trajtimi janë:Te shpjegohet kuptimi dhe vlesra e lirisë së informimit Të shpjegohen principet apo parimet kryesore te ligjit për lirinë e informimit ${ }^{9}$

1. Ç'farë garanton kjo e drejtë, ne nivel kombëtar dhe ndërkombëtar duke përcaktuar qartë se cilat janë burimet e saj. ${ }^{10}$

2. Te interpretohet kjo e drejtë nen kendvështrime të ndryshme duke u mbështetur në nenin 10 të KEDNJ ne praktiken e sjelle prej saj

Të identifikohen institucionet publike te përcaktuara nga Ligji i të drejtës së informimit

1. Të identifikohen ato grupe të cilat kërkojnë informacion dhe çdo konsideratë specifike të cilat duhet të jenë në kërkesat e tyre.

2. Të kalohet procesi I kërkesave për informacion nëpërmjet departamenteve të tyre

3. Të tregohet nga njëra anë lidhja që ekziston ndërmjet hyrjes publike(E drejta për t'u informuar) dhe nga ana tjetër të drejtën për jetën private, paprekshmërinë dhe mbrojtjen e të dhënave personale.Informacioni është oksigjeni i demokracisë.

4. Nëse njerëzit nuk e dinë se çfarë është duke ndodhur në shoqërinë e tyre, nëse veprimet e atyre që i qeverisin janë të fshehura atëhere ata nuk mund të marrin pjesë në mënyrë të kuptishme në punët e asaj shoqërie

5. Për të vendosur një standart me të cilin cilido të mund të masë nëse ligjet vendase e lejojnë në mënyrë të mirëfilltë mundësinë ndaj informacionit zyrtar,ato përcaktojnë qartë dhe saktë rrugët në të cilat qeveritë mund të arrijnë hapje maksimale, në përputhje me standartet më të mira ndërkombëtare.

6. Këto parime përcaktojnë standarte për rregjime kombëtare dhe ndërkombëtare të cilat i japin kuptim të drejtës së lirisë së informacionit.

\footnotetext{
${ }^{6}$ American Revolution in 1775

7 Patric 2006

8 Anastasi A, 2001

${ }^{9}$ Olldashi \&Saliaji 2001

${ }^{10}$ Badlenn 2002
} 


\section{LIRIA E INFORMIMIT - ÇFARË ËSHTË DHE PSE ËSHTË E RËNDËSISHME?}

Në vitin 1946 Asambkeja e Përgjithshme e Kombeve të Bashkuara miratoi një nga rezolutat e saj më të hershme ${ }^{11}$. Ajo konsistonte në :

"Liria e informimit është një e drejtë themelore e njeriut dhe gur provë për të gjitha liritë e përcaktuara nga Kombet e Bashkuara"

Duke patur parasysh që liria e informimit është parë si një nga të drejtat më themelore të njeriut ajo nuk ka një vend të përcaktuar saktë në standartet ndërkombëtare të të drejtave të njeriut. Formulimi i Artikullit 19 për Deklaratën

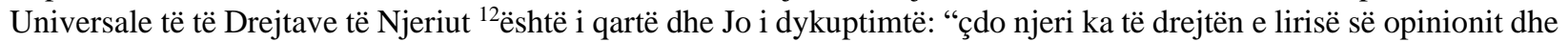
të shprehjes; kjo e drejtë përfshin lirinë për të mbajtur opinione pa ndërhyrjen dhe të thellosh, te ruash e të transmetosh informacionin dhe idetë nëpërmjet shtypit dhe pa patur kufizime"

Ndonëse liria e shprehjes është pare si një përfitim nga të dyja palët ; si nga ata të cilët e "transmetojnë informacionin “ashtu edhe nga ata që e "marrin”atë, ideja që qytetarët janë përcaktuar të kenë të drejtë për t’u informuar për informacionin e mbajtur nga institucionet e qeverisë, nuk ishte e shtrirë në kohë. Suedia e kishte të siguruar të drejtën e informimit me Kushtetutë që nga viti 1776 por ajo është ende një pakicë.Në shumicën e vendeve deri rreth viteve 1940 kanë dominuar disa pikëpamje të cilat ekzistojnë edhe sot Kjo është arsyeja përse formulimi i rezolutës së Asamblesë së Përgjithshme të Kombëve të Bshkuara ${ }^{13}$ ishte një thyerje radikale me të kaluarën.

\subsection{E DREJTA PËR TË DITUR SE ÇFARË BËHET NË PARLAMENT}

Parlamentarët janë përfaqsuesit e publikut-populli i zgjedh ata për të bërë ligje dhe politika.Publiku ka të drejtë të dijë se ç'farë janë duke bërë, në mënyrë që të dinë se si do ta hedhin votën e tyre herën tjetër.Ka disa detyra që kryejnë parlamentarët, për të cilat është mjaft e rëndësishme që qytetarët të jëne të mirinformuar.Puna kryesore e parlamentarëve është të miratojnë ligjet,por ata gjithashtu luajnë një rol kryesor në rishikimin e politikave qeveritare, edhe nëpërmjet debateve ose shumë shpesh përmes komisioneve të specialistëve që ekzaminojnë çështjet e politikave më kryesore.

\subsection{E DREJTA PËR TË DITUR ÇFARË BËHET ME DREJTËSINË}

Ka një thënie të njohur që drejtësia jo vetëm mund të bëjë por “drejtësia” mund të shikohet si duhet bërë”.Me një fjalë, natyra publike e sistemit gjyqësor është një nga mënyrat që tregon se ligji është duke u forcuar dhe pikërisht duke u zbatuar $^{14}$.

Sigurisht një nga arsyet kryesore ${ }^{15}$ që është edhe më e rëndësishme, është që ajo jep një garanci të madhe për dikë që akuzohet për një akuzë penale, siguron që ai të ketë mundësi të gjykohet me korrektësi.Por ky është një interes i gjërë për të gjithë publikun duke bërë të sigurt që sistemi gjyqësor është duke operuar me korrektësi.

H1: “E drejta për informim"një e drejtë që ekziston, pavarësisht të drejtave të tjera apo është thjesht një derivat i lirisë së shprehjes?

Liria e shprehjes në thelb është një e drjtë negative pra është e drejta për të qënë i lirë nga ndërhyrjet me karakter çensurues qofshin këtondërhyrje me origjinë shtetërore apo private.Liria e shprehjes është një mekanizëm kryesisht poltik që mundëson rolin poltik të ${ }^{16}$ individit dhe të grupimeve të ndryshme në jetën poltike të vendit ndonëse ajo

\footnotetext{
${ }^{1111}$ Në vitin 1946 Asambkeja e Përgjithshme e Kombeve të Bashkuara miratoi një nga rezolutat e saj më të hershme Formulimi i Artikullit 19 për Deklaratën Universale të të Drejtave të Njeriut

${ }^{12}$ Formulimi i Artikullit 19 për Deklaratën Universale të të Drejtave të Njeriut, 2004

${ }^{13}$ Asamblesë së Përgjithshme të Kombëve të Bshkuara, pp123

14 Anastasi A, 2005

${ }^{15}$ Formulimi i Artikullit 19 për Deklaratën Universale të të Drejtave të Njeriut,2003

${ }^{16}$ Asamblesë së Përgjithshme të Kombëve të Bshkuara,PP123,156
} 
shikohet edhe si "një mjet për zbulimin e të vërtetës objective" ${ }^{17}$ ose "si mjet për realizimin shpirtëror dhe intelektual të individit".

Nga ana tjetër në contrast të plotë më natyrëne lirisë së shprehjes, e drejta për informim e quajtur ndryshe e drejta për të ditur është një e drejtë positive e cila dikton veprim nga shteti për të mundësuar realizimin e saj.Pra në rast se pranojmë se e drejta për t'u informuar është një derivate i lirisë së shprehjes del në pah filozofia që qëndron pas ideimit të së drejtës për informim, sipas së cilës kurrsesi nuk mjafton sanksionimi i së drejtës për të folur dhe për të shkruar lirisht për të thënë që liria e shprehjes gëzohet efektivisht.

Liria e shprehjes presupozon dhe sigurimin e shtetit të mjeteve për ta ushtruar siç duhet atë. Liria e shprehjes nuk mund të ushtrohet siç duhet për aq kohë që kushtet për t'u shprehur nuk ekzistojnë si psh: e drejta dhe mundësia reale për t'u informuar në lidhje me punët e shtetit, për mundësinë për t'u organizuar tubime të ligjshme, mundësinë për të operuar lirisht (dhe me përgjegjësi) në tregun mediatik etj. ${ }^{18}$ Liria e shprehjes konsumohet kryesisht në media dhe nga njerëzit e medias ose të politikës në ndjekje të interesit public, e drejta për t'u informuar është më egocentrike në kuptimin që ajo i shërben në rradhë të parë interesave të ngushta të individit.E drejta për informim ${ }^{19}$ figuron më vete në një nen të "Kushtetutës së Republikës së Shqiprisë” nga pikëpamja formale-teknike, liria e shprehjes dhe e drejta për informim duken si dy të drejta të ndryshme por në të vërtetë nuk është kështu.

Është e vërtetë që liria e shprehjes është një e drejtë negative në kuptimin se do të mjaftonte mosveprimi nga ana e shtetit që ajo të gëzohej efektivisht nga përdoruesit e saj por, nga ana tjetër liria e shprehjes do ta humbte kuptimin e saj të vërtete (kontributi për jetën politike, zbulimi i të vërtetës objective, realizimi intelektual dhe shpirtëror i individit etj) në qoftë se ajo nuk do të plotësohej me disa të drejta të tjera positive si e drejta për t'u informuar. ${ }^{20} \mathrm{E}$ drejta e replikës në shtyp e television, e drejta e tubimit ${ }^{21}$ apo e pjesëmarrjes në forume të ndryshme publike(gjykatë,këshillbashkiak etj)

\section{TË MIRAT E LIRISË SË INFORMIMIT}

Kur disa institucione të rëndësishme argumentojnë se është më mirë për të mbajtur të rezervuar nga publiku informacionet, zakonisht thonë që kjo është “për të mirën tuaj”.Ne realitet argumenta të tillë mund të shfaqen të gabuar.Por ata injorojnë edhe një pyetje të rëndësishme.Ideja që qeveritë mbajnë informacion, sepse kjo i shërben të mirës së publikut është një pikëpamje antidemokratike e marrëdhënieve midis saj dhe popullit.Argumenti kryesor në favor të lirisë së informimit është që ai nuk i ${ }^{22}$ përket qeverisë por popullit si i tërë.

Të mirat e lirisë së informimit do të ishin:

Më pak korrupsion

5. Individët dhe institucionet bëhen të korruptuar kur nuk ka vëzhgim të asaj çfarë bëjnë.

6. Sa më shumë që ata të operojnë nën vëzhgimin e rreptë të publikut aq më pak të korruptuar janë dhe më shumë efiçentë

\section{Mungesa e urisë}

Kjo mund të duket si diçka e çuditshme të vendoset në këtë listë.Fituesi i çmimit Nobel, ekonomisti Amartya Sen ka argumentuar se " mungesa" e ushqimit nuk ndodh në ato vende me shtyp të lirë por nga mosveprimi i qeverive. Qeveritë nuk guxojnë të jenë joaktive në një çështje kaq të rëndësishme kur ata janë subject i vëzhgimit constant të mediave

Një shoqëri më e shëndetshme

Edhe kjo mundtë duket si diçka e çuditshme që të përfitojë nga liria e informimit.Duke e konsideruar si krizën më të madhe të shëndetit public të kohëve tona, HIV-AIDS, që është përhapur kudo.Në vitet e para, infeksioni i Hiv ishte i aftë të shpërndahej me shpejtësi, pasi mungonte informacioni public rreth virusit dhe mënyrës se si të evitohej

\footnotetext{
17 J.S.Mill,"On Liberty"

${ }^{18}$ Asamblesë së Përgjithshme të Kombëve të Bshkuara, pp321

${ }^{19}$ Cottler 1973

${ }^{20}$ Asamblesë së Përgjithshme të Kombëve të Bshkuara, gjykata e RSH viti 2003

21 Thomai E 2001

${ }^{22}$ Formulimi i Artikullit 19 për Deklaratën Universale të të Drejtave të Njeriut, 2001
} 
ai.Vendet që kishin programe efektive informimi për publikun kanë qënë të afta të kthejnë drejtimin e infektimit me hiv

Një ambient më i pastër

1. Shumica e vendimeve që i shkaktojnë dëme ambientit merren me dyer të mbyllura.Shumica e këtyre vendimeve, mund edhe të evitoheshin, në qoftëse vendimet që merren kishin për t’u shoqëruar me një studim mbi impaktin në ambient- $i$ cili duhet të bëhet $i$ vlefshëm për publikun.

2. Dhunimi i të drjtave të njeriut, ashtu si dhe korrupsioni lulëzon nën klimën e mbylljes, sekretit.

Disa nga dhunimet më të rënda të të drejtave të njeriut, të tilla si tortura janë gjithmonë diçka që zënë vend vetëm pas mbylljes së derës. Një qeveri e hapur -duke përfshirë për shembull publikimin e hetimeve sipas dëshmive të dhunimit të të drejtave të njeriut -është më shumë e prirur për të patur rezultate në respektimin e të drejtave të njeriut

Respektimi i jetës private

Pa lirinë e informimit nuk ka asgjë që të garanton që qeveritë dhe institucionet e tjera të saj nuk do të grumbullojnë sasi të mëdha informacioni rreth individëve.

Nëqoftëse individët kanë gjithmonë të drejtë të shikojnë se ç'farë informacioni ${ }^{23}$ është mbajtur rreth tyre, e drejta për privatësi ka më shumë mundësi të respektohet. ${ }^{24} \mathrm{Në} \mathrm{këtë} \mathrm{kuptim} \mathrm{njerëzit} \mathrm{kanë} \mathrm{të} \mathrm{drejtën} \mathrm{të} \mathrm{sigurohen,} \mathrm{që}$ informacioni i mbajtur për ta është i saktë.Në se ai nuk është i tillë, mund të merren vendime të gabuara dhe të dëmshme

Një shoqeri më e sigurtë

Argumenti në favor të sekretit zyrtar është pikërisht nevoja për mbrojtjen e "sigurisë kombëtare".Ekzaminimi public I vendimeve të lidhura me mbrojtjen është i nevojshëm për një shoqëri më të sigurt.Fshehtësia drejton korrupsionin dhe bën joefiçente shërbimet secrete.

Liria për të kritikuar qeverinë mbështet hapur nga gjykata në 1986:"është detyra e shtypit të japë informacion dhe ide mbi çështjet politike,ashtu si mbi ato në fushat e tjera të interesit public.Jo vetëm shtypi ka të drejtën të japë informacione të tilla por edhe publiku ka një të drejtë për t'i marrë ato" ${ }^{25}$

Liria për të dhënë informacion dhe ide është plotësuese e lirisë për të marrë informacion dhe ide.Kjo është e vërtetë përsa i përket medias së shkruar,si dhe medias të transmetimeve .Në lidhje me këtë të fundit gjykata është shprehur se "shtetet nuk duhet të ndërhyjnë midis transmetuesit dhe marrësit,duke qënë se ato kanë të drejtën për të hyrë në kontakt të drejtpërdrejtë me njeri tjetrin sipas dëshirës së tyre "për të dhënë informacion dhe ide çështjet ekonomike garantohen nga neni 10,por në çështjet ekonomike autoritetet vendase kanë një liri më të gjërë vlerësimi .Krijimet artistike dhe performaca si dhe shpërndarja e tyre konsiderohet nga gjykata si një kontribut madhor në shkëmbimin e ideve dhe mendimeve, një komponent themelor i një shoqërie demokratike .Komisioni argumenton duke u shprehur se liria artistike dhe qarkullimi i lirë i artit kufizohen vetëm në shoqëri jodemokratike:

"Nëpërmjet punës krijuese artisti shpreh jo vetëm një vision personal të botës po edhe pikëpamjen e tij për shoqërinë në të cilën jeton.Për këtë arsye arti jo vetëm ndihmon formimin e mendimit public,por është edhe shprehje e tij "26

Dallimi midis informacionit dhe mendimeve

Bëhet një dallim i qartë midis informacionit ose (fakteve) dhe mendimeve(gjykimet mbi vlerat) Gjykata është shprehur:

"Ekzistenca e fakteve mund të demonstrohet kurse e vërteta e vlerave nuk është e prekshme si provë.Në lidhje me gjykimet mbi vlerat kjo kërkesë është e pamundur të përmbushet dhe dhunon vetë lirinë e mendimit,e cila është pjesë themelore e të drejtës së siguruar nga neni 10."

Ndërsa mendimet janë pikëpamje ose vlerësime personale të një ngjarjeje ose situate dhe nuk janë të prekshme si prova për të qënë të vërteta ose të gënjeshtërta, faktet e parashtruara mbi të cilat mendimet bazohen mund të jenë të mundshme për t'u vërtetuar sit e vërteta apo të gënjeshtërt ${ }^{27}$.

Në të njëjtën mënyrë gjykata në Dalban u shpreh:"Do të ishte e papranueshme për një gazetar që t'i hiqet e drejta për të shprehur gjykime subjective kritike, përderisa ai mund ta vërtetojë të vërtetën që thotë"28

\footnotetext{
${ }^{23}$ Asamblesë së Përgjithshme të Kombëve të Bshkuara, pp345

${ }^{24}$ Zejneli I, 2009

25 "Lingens kundër Austrisë" i datës 11.10.1986 A.103,par,82

${ }^{26}$ Komisioni i 8 tetorit 1986

${ }^{27}$ Zejneli I, 2009

Anastasi A, 2007

28 “Dalban kundër Rumanisë" 1999
} 
Si rrjedhojë bashkë me informacionin ose të dhënat që mund të verifikohen mendimet,kritikat ose spekullimet që mund ${ }^{29}$ të mos provohen si të vërteta gjithashtu mbrohen nga neni 10 .Gjykimet subjective në veçanti ato të shprehura në fushën politike gëzojnë një mbrojtje të veçantë si një kërkesë për pluralizmin e mendimeve që është vendimtare për një shoqëri demokratike .

Garantohen edhe mendimet e shprehura në gjuhë të fortë ose të ekzagjëruar,shkalla e mbrojtjes varet nga përmbajtja dhe qëllimi i kritikës.

1. Në çështjet e interesit publik gjatë debateve politike, në fushata elektorale ose aty ku kritika bëhet në nivele qeveritare tek politikanët ose autoritetet publike mund të priten fjalë të rënda dhe kritika të ashpra dhe do të tolerohen në një shkallë më të madhe nga Gjykata

2. Në "Thorgeirson kundër Islandës" ${ }^{30}$ gjykata zbuloi se megjithëse artikujt mbartnin terma të rënda, gjuha nuk mund të konsiderohet e tepruar duke patur parsysh qëllimin e artikullit,i cili ishte të nxiste reformën në polici. Dallimi midis fakteve dhe mendimeve dhe ndalimi i kërkesës për prova në lidhje me këtë të fundit bëhet mjaft $i$ rëndësishëm në sisteme ligjore vendase që akoma e parashtrojnë këtë kërkesë si krim për fyerje.Në lidhje me faktet gjykata e ka njohur mbrojtjen në bazë të qëllimit të mirë duke i lënë medias një hapsirë ku mund të pranohen gabimet.

\section{LIRIA PËR TË MARRË INFORMACION DHE IDE}

Liria për të marrë informacion dhe ide përfshin të drejtën për të mbledhur informacion dhe për të kërkuar informacion nëpërmjet të gjitha burimeve të mundshme ligjore.Liria për të marrë informacion mbulon gjithashtu edhe transmetimet televizive ndërkombëtare ${ }^{31}$ Ndërsa liria për të marrë informacion dhe ide lidhet me median me qëllim që të mundësojë këtë të fundit të shpërndajë një informacion dhe ide të tillë publikut,gjykata gjithashtu e interpreton këtë të drejtë si të drejtën e publikut për t’u informuar në mënyrën e duhur, në veçanti për çështjet e interesit public.

\section{LIRIA E SHTYPIT}

Megjithëse neni 10 nuk përmend në mënyrë të hapur lirinë e shtypit gjykata ka zhvilluar jurisprudencë të gjërë duke formuar një grup parimesh dhe rregullash që i japin shtypit status të veçantë në gëzimin e lirive që përbëjnë nenin 10.Viktimat e dhunimit të së drejtës për lirinë e shprehjes nga ana e autoriteteve publike janë gazetarët më shumë se sa individët e tjerë.Roli I shtypit si një mbikqyrës u vu në dukje për herë të parë nga Gjykata në çështjet gjyqësore të "Lingens kundër Austrisë̈ $e^{32}$ "; "Oberschlik kundër Austrisë" (1) ${ }^{33}$ dhe "Oberschlik kundër Austrisë" (2) ${ }^{34}$ editorët e periodikëve politikë kishin botuar artikuj që kritikonin politikanët për politikat e tyre publike në lidhje me probleme të politikës.

1. Secili nga politikanët i hodhi aplikantët privatisht në gjyq ${ }^{35}$ për shpifje dhe të gjitha proceset, përfunduan në favor të tyre.

2. Aplikantët pretenduan se vendimet e gjykatave austriake shkelnin lirinë e tyre të shprehjes në bazë të nenit 10.

Duke vënë re çështjën Ligens Gjykata ra dakort se:

"Liria e shtypi i jep publikut një nga mjetet më të mira për të zbuluar dhe krijuar një mendim përreth ideve dhe qëndrimeve të udhëheqësve politikë

Më në përgjithësi liria e debatit politik është pikërisht në qëndër të konceptit të një shoqërie demokratike e cila mbizotëron në të gjithë Konventën."

1. Gjykata kritikoi ligjin austriak për shpifjen i cili ngarkon të akuzuarit për barrën e provës ${ }^{36}$ për vërtetimin e pohimeve të veta,duke qënë e mendimit se kjo mund të përbëjë një shkelje të nenit 10.

Lira e shtypit i jep publikut një nga mjetet më të mira për të zbuluar dhe për të formuar, një mendim mbi idetë dhe qëndrimet e drejtuesve politikanë dhe liria e debatit politik është në thelb të një shoqërie demokratike

\footnotetext{
${ }^{29}$ Dowlann 2001

30 “Thorgeirson kundër Islandës” I vitit 1992

${ }^{31}$ Lingens kundër Austrisë” I datës 11.10.1986 A.103,par,82

32 “Lingens kundër Austrisë” I datës 11.10.1986 A.103,par,82

33 "Oberschlik kundër Austrisë" I datës 23.05.1991 A.204,par,59

34 Oberschlik kundër Austrisë” I datës 01.07.1997,par,29

35 Thorgeirson kundër Islandës" I vitit 1992

${ }^{36}$ Thorgeirson kundër Islandës" I vitit 1993
} 


\section{KONKLUZIONE TË PËRGJITHSHME}

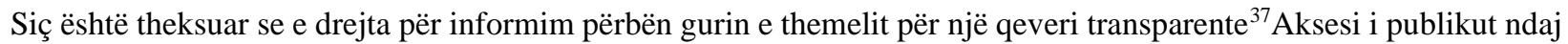
informacionit është në fakt një komponent themelor i një shoqërie demokratike.Ajo zë një vend të rendësishem si një nga të drejtat më themelore të njeriut dhe përbën bazën për garntimin e të drejtave të tjera. . Nuk ka vend të lirë nuk ka demokraci pa pasur një garantim të gjërë të së drejtës për lirinë e shprehjes, të garantuar nga gjykata të pavarura dhe të paanshme

Ekzistojnë një sërë ligjesh,dokumentash, konventash e marrëveshjesh të cilat kanë si objekt të tyre të drejtën e informimit, të cilat vendosin standarte të tilla që e bëjne të detyrueshme që ligjet për të drejtën e informimit duhen hartuar në ate mënyre që të ekzistojë një ekulibër midis të drejtës për informacion dhe të drejtës për të mbrojtur të dhënat personale ose informacion me rëndësi madhor.

1. Sanksionimi në ligje apo dokumenta të ndryshme përbën kuadrin ligjor të së së drejtës për t'u informuar por gjithashtu dhe ekzistenca e një akti të së drejtës së informimit është i nevojshëm për të pasur një proçedurë të pastër, efiçente dhe të përcaktohet qartë qellimi i lirisë së informimit.

2. Ajou jep qytetarëve informacion, pra që i lejon ata të ushtrojnë të drejtat e tyre dhe për këtë duhet të kemi garancinë që na nevojitet për sigurimin e një pjese të informacionit çdo herë që ne e kërkojmë atë, sepse ndryshe nuk mund t'i ushtrojmë të drejtat e tjera.

3. Principet apo parimet bazë të së drejtës së informimit përcaktojnë standarte për rregjime kombëtare dhe ndërkombëtare të cilat i japin kuptim të drejtës së lirisë së informacionit.

Kur flasim rreth principeve të lirisë së informimit, ekzistojnë disa kategori informacionesh që mund të përjashtohen nga rregullat e përgjithshme të së drejtës së publikut.Janë qëllimet legjitime ato që justifikojnë mos ekspozimin.Kjo listë përfshin vetëm interesat që përbëjnë baza legjitime për refuzimin e ekspozimit të dokumentave dhe duhet kufizuar për çështje të tilla si zbatimi i ligjit, siguria kombëtare por nuk mjafton që informacioni thjesht të përfshihet brenda shtrirjes së një qëllimi legjitim të rradhitur në ligj .

1. Informacioni public duhet të tregojë që ekspozimi i informacionit do t'i shkaktonte dëm thelbësor atij qëllimi legjitim por gjithnjë duhet patur parasysh interesin madhor public.

2. E drejta për informim dhe e drejta për një jetë private janë konsideruar si të drejta të cilat për nga rëndësia e tyre shërbejnë për ndërtimin e një shteti demokratik

3. Në lidhje me detyrimin e administrimit të pranimit të hyrjes publike të dokumenteve është i limituar nga detyrimi për të mbrojtur të drejtat personale, vendi i bashkimit nyja e leximit e legjislacioneve më të shumta në hyrjen publike dhe në mbrojtjen e të dhënave përshkuan nevojën për të gjetur një balancë midis dy të drejtave

Aksesi në të drejtën e informimit ndihmon të ndërtohet besimi i qytetarëve në institucionet publike dhe të forcojë efektivitetin e tyre.E drejta për informim synon një administrim public më të mirë, të reduktojë korrupsionin dhe të përmirsoje shërbimet publike dhe të fuqizojë pjesëmarrjen e publikut në procesin e vendimmarrjes.

\section{LITERATURA}

Raporti special në Kombet e Bashkuara mbi të Drejtat e Njeriut par.35

Kushtetuta e Republikës së Shqiprisë, Tiranë 21 tetor 1998

Konventa e Aarhusit 26.10.2000

Ligji Numër 8457 datë 11.02.1999” Për Informacionin e Klasifikuar Shtetëror”

Ligji numër 8391 datë 28.10.1998 "Për Shërbimin Informativ Kombëtar"

Ligji numër 8503 datë 30.06.1999 "Për të drejtën e Informimit Për Dokumentat Zyrtare"

Ligji numër 8517 datë 22.07.1999 "Për mbrojtjen e të dhënave personale"

Ligji numër 8485 datë 12.05.1999"Kodi i Procedurave Administrative i Republikës së Shqiprisë”

Ligjinumër 8549 datë 11.11.1999"Statusi i nënpunësit civil”'

Ligji numër 8454 datë 04.02.1999" Për Avokatin e Popullit"

Ligji numër 8410 datë 30.09.1998 "Për Radion dhe Televizionin Publik e Privat në Republikën e

Shqiprisë"

Ligji numër 7756 datë 11.10.1993" Për Shtypin"

Ligji numër 8004 datë 07.12.1995 "Për Konkurrencën"igji numër 7827 datë 31.05.1994 "Për Avokatinë"

Ligji numër 7829 datë 01.06. 1994"Për Noterinë"

Ligji numër 7638 datë 19.11.1992 "Për Shoqëritë Tregtare

\footnotetext{
${ }^{37}$ Lingens kundër Austrisë” I datës 11.10.1986 A.103,par,89
} 